\title{
Coping with repetitive-motion injuries in a large academic library
}

\author{
University Librarian \\ Texas A U M University \\ Koriyama, Japan
}

By Richard A. Eissinger and Thomas W. Ricks

Science Reference Librarian

University of Colorado at Colorado Springs

\section{Are your workstations user-friendly?}

$\mathbf{R}$ eports from the public and corporate sectors in recent years have revealed dramatic increases in worker injuries related to repetitive actions or motions. For employers these injuries translate to lost time, reduced productivity, and increased benefits costs. A recent National Institute for Occupational Safety and Health (NIOSH) investigation of the newspaper industry in the U.S. established a significant relationship between computer terminal usage and the incidence of repetitive motion injuries. ${ }^{1}$ Some health care officials are predicting that this type of injury will be the number one occupational hazard of the $1990 \mathrm{s.}^{2}$

Libraries are just beginning to recognize and acknowledge the existence of these problems. The Sterling C. Evans Library at Texas A\&M University is an example of a large academic library where a good deal of repetitive work is conducted by staff using computer terminals. With a large centrally located facility, holdings over 1.9 million volumes, a fully integrated online system, and a full range of electronic reference services, most of the 137 classified staff and 57 professionals spend some time working with computer terminals.

In January 1991, prompted by increasing complaints and several reported wrist injuries among library staff, the Evans Library Staff Association formed a committee to investigate these incidences. The staff committee was composed of professional and paraprofessional librarians, who set out to investigate the complaints and to formulate recom- mendations to the library administration on methods to deal with this continuing problem. The committee searched the literature of repetitive motion injury, circulated a questionnaire among the librarystaff, and consulted professional occupational therapists for input.

\section{Investigation of the problem}

A literature survey revealed expressed concern through publishing activity in business and government sectors, with little activity reported from the library quarter. No reports were found on how academic libraries are dealing with these problems. One recent study did address repetitive motion injuries in large public libraries through a survey of management response to incidence of these injuries. ${ }^{3}$

The committee then designed and circulated a questionnaire to the Evans Library staff to ascertain the number of work-related injuries in the library and to establish the level of the staffs' concerns and knowledge on repetitive-motion injuries.

The questionnaire was distributed to 194 library staff members and sought candid response by assuring anonymity. Most of those returned (68 individuals, $35 \%$ ) included lengthy commentary. Many ( 43 individuals, $63 \%$ of the respondents) identified specific complaints due to their workstation environments such as neck and backache, sore arms, and headache. Most of those responding indicated 
that they shared workstations with other individuals and that they had only marginally adjustable workstation equipment. These factors severely limit the ability to properly adjust work conditions to the individual. worker. The majority (35 individuals, $51 \%$ of the respondents) asked for more information on repetitive-motion injuries and on how to properly adjust workstation equipment. A surprising number of individuals (7 library staff, $11 \%$ of the respondents) reported prior or present treatment by a physician for some type of repetitive-motion injury. These responses prompted the committee to seek outside professional advice in studying these problems.

The committee consequently approached a community health care provider, Scott \& White, Inc., that agreed to conduct a thorough library evaluation. A group of Scott \& White physical and occupational therapists then inspected library workstations and interviewed staff about their work environment concerns. The therapists' recommendations included a program to modify existing workstations to provide a safer and more productive work environment, and outlined suggestions for educating the staff in the proper utilization of the existing workstations. They suggested that a program of stretching exercises and provision for frequent breaks for operators would help to relieve some of the physical stress at the computer workstation. They outlined suggestions for providing educational information for staff workers, and provided guidelines on the selection of ergonomic chairs and equipment. They concluded their evaluation with recommendations that the library conduct a periodic review of the program to include systematic data collection (noting lost days, number of injuries, type of injuries, and library areas where injuries occurred) and a scheduled assessment of the program by trained professionals.

\section{Recommendations of the committee}

The library committee then recommended that the Library Administration consider several actions that would have immediate benefit. These actions included altering work schedules to accommodate more frequent breaks, rotating job assignments to minimize repetitive motions, providing staff with examples of stretching exercises to minimize stress, and conducting an inventory of existing workstations to identify specific problem areas. It was stressed that these efforts involve minimal initial cost and have the immediate benefit of building awareness of the existence of these problems among library staff. However, the committee noted that long-term solutions would require extensive planning, much greater expense, and a long-term commitment by the administration. Purchase of ergonomic equipment and workstation enhancements must be accompanied with staff education and training programs and an ongoing evaluation program to ensure a continual awareness.

Evidence of how effectively library staff and administration can work together in addressing these problems is evidenced by a recent commitment by the library director to purchase several new ergonomic workstations as an initial step in solving the problem. In addition, a group has been selected from among the library staff to begin the design and implementation of a preventive training program based on the committee's recommendations.

\section{Conclusions}

This paper can serve as an outline for all libraries, regardless of size or type, that seek to reduce the potential for repetitive-motion injuries among library staff. Encouraging a cooperative atmosphere between library staff and administration is important in recognizing and addressing the problem. When repetitive-motion injuries are suspected or discovered in the library, librarians have the obligation to their colleagues in the library, to the profession, and to their library patrons to investigate the matter and encourage change where appropriate and feasible. Not only is the health of the employees at risk, but these injuries can be expensive in terms of rehabilitation and loss of productivity. This process can sometimes be politically and financially unpopular with some administrators, but if approached systematically and collectively the process of evaluation and recommendation has a greater chance of success. We should not wait for others outside the library to impose changes.

New technologies will continue to be implemented by libraries. Librarians must be aware of the potential problems that come with these technologies. Some of the incidents of repetitive-motion injury reported at Sterling C. Evans Library have been workstation related, but many are due to lack of education and understanding of the problem. Working within a cooperative rather than an adversarial environment has allowed the fullest use of these new technologies where productivity and a healthy work environment can both exist.

\section{NOTES}

${ }^{1}$ Jim Castelli, "Review commission stands ready to arbitrate OSHA disputes," Safety \& Health (August 1990): 32-34.

${ }^{2}$ Peter A. Susser, "Washington scene: Growing concern for workers' repetitive motion injuries has made their prevention OSHA's issue of the nineties," Employment Relations Today I6 (Autumn 1989): 243-48.

${ }^{3}$ James M. Kusack, "The light at the end of the carpal tunnel," Library Journal 115 (July 1990): 56-59. 
"The best reference help for today's job seekers."

Syndicated columnist Joyce Lain Kennedy says, "The corporate briefs are to job seekers what annual reports are to investors... It's a bargain."

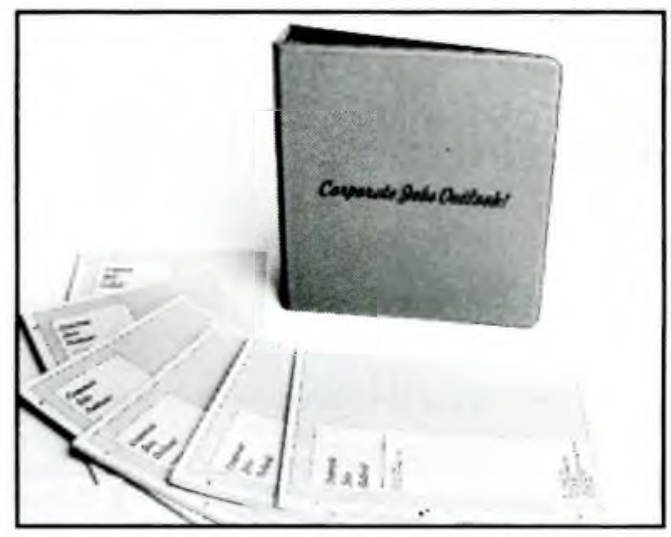

\section{Corporate Jobs Outlook!}

How can you really help people seeking jobs?

With our timely, objective "Reports" on major employers! You'll get details on growth plans, salaries, benefits, financial stability, training, hiring, advancement opportunities, and corporate culture. You'll receive Reports on 100 corporations yearly. Published by the author of the acclaimed book, The Almanac of American Employers.

That's why CJO is used by outplacement experts, by the personnel departments of AT\&T and most of the Fortune 500 firms, by placement offices and libraries at top universities such as CalTech, Yale, and Northwestern, and by researchers at such places as The World Bank. A subscription includes bimonthly issues of Reports on growing, hiring, nationwide employers; a cumulative index by industry; geographic indexes; access to previous Reports on over 500 firms; imprinted binder; free shipping; and free replacement of lost or damaged pages.

....."Your publication provides information that is not readily available in any of our other sources." Cook County Public Library

....."We appreciate the research and up-to-date information you provide. The wording is great, easily read and interesting." NW Missouri StateUniv.

1-year subscription \$159.99. 100\% Satisfaction Guarantee! (Best Buy: for $\$ 239.99$, get a one-year back issue collection PLUS one year forward subscription.)

CJO, P. O. Drawer 100, Boerne, TX 78006

Ph: 512-755-8810, FAX: 512-755-2410

ISSN 0892-5232, Federal ID 74-2440918

LOOK FOR US AT ACRL 